\title{
PROCESSO DE FORMAÇÃO DE ANIMADORES SOCIOCULTURAIS EM PROJETOS DE EDUCAÇÃO FORA DO AMBIENTE ESCOLAR ${ }^{1}$
}

\author{
Recebido em: 28/11/2017 \\ Aceito em: 19/04/2018 \\ Paula Leite Antunes de Macedo ${ }^{2}$ \\ Gislane Ferreira de Melo $^{3}$ \\ Universidade Católica de Brasília \\ Brasília - DF - Brasil \\ Tânia Mara Vieira Sampaio ${ }^{4}$ \\ Instituto Federal de Goiás - Campus Luziânia \\ Luiziânia - MG - Brasil
}

\begin{abstract}
RESUMO: A educação em projetos fora do ambiente escolar é uma possibilidade no processo de ensino-aprendizagem. Os objetivos deste trabalho foram verificar se o lazer, vivenciado por meio de um projeto dessa natureza, pode promover um processo de educação e identificar a percepção de 5 futuros animadores socioculturais sobre lazer, educação e a relação entre ambos. Os resultados obtidos indicam que o lazer contribui para a formação dos participantes do projeto por meio da educação para e pelo lazer. Os futuros animadores socioculturais apresentam vontade e percepção positiva quanto à utilização do aspecto educacional do lazer e de seus benefícios, e acreditam que a vivência contribuirá na formação pessoal, social e curricular dos alunos. Conclui-se que há a necessidade de formação continuada e de atenção especial dos monitores com o próprio lazer, e da instituição de uma equipe multidisciplinar para atuar na área.
\end{abstract}

PALAVRAS CHAVE: Atividades de Lazer. Educação.

\section{SOCIO-CULTURAL ANIMATOR TRAINING PROCESS IN EDUCATION PROJECTS OUTSIDE THE SCHOOL ENVIRONMENT}

ABSTRACT: Education in projects outside the school environment is a possibility in the teaching-learning process. The objectives of this study were to verify if leisure, experienced through such a project, can promote a process of education and identify the perception of 5 future socio-cultural animators on leisure, education and the relationship

\footnotetext{
${ }^{1}$ Artigo premiado no $29^{\circ}$ Encontro Nacional de Recreação e Lazer (ENAREL), realizado em Caruaru/PE em 2017.

${ }^{2}$ Mestranda em Gerontologia pela Universidade Católica de Brasília.

${ }^{3}$ Doutora em Educação Física e Pós-Doutorado em Psicologia do Esporte e do Exercício. Docente da Universidade Católica de Brasília.

${ }^{4}$ Doutora e Pós-Doutorado em Estudos do Lazer pela UFMG. Docente do Instituto Federal de Goiás Campus Luziânia.
} 
between both. The results indicate that leisure contributes to the development of project participants by means of education for and through leisure. Future socio-cultural animators are willing and positive about the use of the educational aspect of leisure and its benefits, and believe that the experience will contribute to the personal, social and curricular formation of the students. It is concluded that there is a need for continuous training and special attention of the monitors with their own leisure, and the institution of a multidisciplinary team to work in the area.

KEYWORDS: Leisure Activities. Education.

\section{Introdução}

\section{Sobre o lazer}

Lazer é um tema muitas vezes negligenciado pela humanidade, vítima de preconceitos e frequentemente associado à ideia de inutilidade, em especial no Brasil, o famoso país do "carnaval e futebol". De fato, essa não é uma ideia equivocada, visto que durante anos imperou no mundo, em especial no hemisfério ocidental, a moral cristã, que condenava o não-fazer-nada e supervalorizava o trabalho (CAMARGO, 2002; MARCELLINO, 1996). Segundo Camargo (2002), até os dias de hoje há um incômodo em relação ao lazer e à diversão por parte da totalidade das doutrinas religiosas cristãs.

A ideia de divertimento sempre coexistiu com o próprio ser humano e nunca precisou de momento específico para acontecer. É algo natural, que não precisa de horário nem local específico para isso, pois é possível se divertir em qualquer ocasião. É a visão de lazer como uma necessidade humana, repleta de ludicidade e presente no cotidiano das pessoas (GOMES, 2014). No entanto o conceito usual de lazer nasceu nos tempos de Revolução Industrial, fruto de lutas dos trabalhadores, ao ser antagonizado com o trabalho, em uma clara divisão de propostas de tempo. Eis aí a primeira grande característica do lazer: o tempo, que de acordo com Melo e Alves Junior (2003), possui um caráter objetivo e social. Assim, o tempo passível de se praticar o lazer, de forma 
ativa ou contemplativa é o "tempo livre das obrigações, sejam elas profissionais, religiosas, domésticas ou decorrentes das necessidades fisiológicas" (MELO; ALVES JÚNIOR, 2003, p.31).

A palavra lazer, para a qual não há tradução literal em todas as línguas, vem do latim licere, e significa "ser lícito, ser permitido, pode-se fazer" (ROLIM, 1989, p. 51). Esse termo tem ligação estreita com a ideia de ser livre para se fazer o que se quer, o que lhe dá prazer. E essa é sua segunda grande característica: o prazer, de caráter subjetivo e individual, segundo Melo e Alves Junior (2003). Essa condição é explicada por Rolim (1989, p. 55), que afirma que “a primeira condição para existir o lazer é a pessoa se encontrar num estado de satisfação. É o 'Ah! Isso me interessa!' que afasta para longe as tensões que toda concentração e atenção obrigatórias produzem".

Ao buscarmos uma definição de lazer, verificamos que a de Dumazedier (1973) é das mais citadas. Segundo ele, lazer é definido como:

[...] um conjunto de ocupações às quais o indivíduo pode entregar-se de livre vontade, seja para repousar, seja para divertir-se, recrear-se e entreter-se, ou ainda para desenvolver sua informação ou formação desinteressada, sua participação social voluntária ou sua livre capacidade criadora, após livrar-se ou desembaraçar-se das obrigações profissionais, familiares e sociais.

Nesse conceito verificam-se aspectos contidos na proposta de classificação das atividades de lazer em interesses culturais físicos, estéticos/artísticos, manuais, intelectuais e sociais.

Os interesses culturais físicos são atividades que buscam o bem-estar pela movimentação do corpo e são procuradas por pessoas com certa preocupação com a melhoria e manutenção da saúde. Dentro dessa categoria se encaixam as mais diversas práticas esportivas (MELO, ALVES JÚNIOR; 2003). 
Os interesses culturais estéticos e artísticos são revestidos do senso de beleza, onde o imaginário é o que importa e a proximidade com a realidade não possui relevância (SILVA, SAMPAIO; 2011). Historicamente, o acesso ao conteúdo artístico é restrito a uma pequena parcela da população, sendo a arte, na maior parte das vezes, associada à cultura erudita. Contudo, para a maior parte da população, o contato fica limitado apenas às culturas de massa, ou seja, aquela produzida pela indústria cultural para o consumo em larga escala (MELO, ALVES JÚNIOR; 2003).

Já os interesses culturais manuais são associados à "capacidade de manipulação, quer para transformar objetos ou materiais - por exemplo, o artesanato e o bricolage quer para lidar com a natureza, como no caso da jardinagem e o cuidado com animais" (MARCELLINO, 1996, p. 18).

Os interesses culturais intelectuais são representados, por exemplo, por jogos como o xadrez e dama e se caracterizam pelo "domínio do real sobre o imaginário, físico e social, estando relacionado a ocasiões em que a busca do prazer está ligado diretamente às oportunidades que têm o raciocínio nas oportunidades de lazer como ponto central" (SILVA; SAMPAIO, 2011, p. 55).

Por fim, de acordo com essa proposta de classificação inicial, temos os interesses culturais sociais, os quais são pautados nas relações e convívios sociais, ou seja, no contato olho no olho. Como exemplos específicos desse interesse cultural temos encontros em cafés, bailes, bares e as associações de diversos interesses às quais podem ser frequentadas (MARCELLINO, 1996).

Essa classificação dos interesses culturais posteriormente foi ampliada ao se inserir o interesse cultural turístico que é associado à quebra do cotidiano ao se entrar em contato com novas paisagens e culturas. Nota-se nesse conceito uma característica 
dessas atividades: elas não dependem de deslocamento para outros municípios ou países, podendo o indivíduo exercê-la dentro de seu espaço cotidiano, ou seja, utiliza-se sua própria cidade como equipamento de lazer. Faz-se importante frisar esse aspecto, pois ele torna-se uma oportunidade de usufruto do lazer e de ocupação dos espaços da cidade de forma consciente, o que contribui para a formação cidadã (SILVA; SAMPAIO, 2011).

Finalmente, em função dos grandes avanços tecnológicos vivenciados nas últimas décadas, Schwartz (2003) propõe a mais nova categoria de interesse cultural do lazer: o interesse cultural virtual. Segundo Silva e Sampaio (2011), o que se torna importante constatar é que os recursos virtuais ampliaram as possibilidades de acesso a outros interesses culturais do lazer, haja vista a oportunidade que proporcionam, dentre tantas, de conhecer pontos turísticos em qualquer parte do mundo, de ampliar e manter os relacionamentos em geral, de assistir espetáculos e filmes, de acessar informações de forma fácil, ou até mesmo de praticar exercícios físicos por meio de jogos eletrônicos. O mundo virtual proporciona diversas oportunidades às pessoas que, sem ele, muitas vezes não teriam condições financeiras de vivenciá-las.

O que vai determinar em qual interesse cultural uma atividade de lazer será inserida é o objetivo que levou determinada pessoa a praticar aquela atividade, ou seja, a busca pelo lazer envolve a satisfação de aspirações dos seus praticantes. Essa reflexão induz à constatação de mais uma característica do lazer: a opção. Assim, cada pessoa escolhe como exercerá seu lazer de acordo com seus gostos. Mas, como falar de preferências quando não se conhece o todo? O cenário ideal seria que cada pessoa pudesse praticar e exercitar as várias formas e os interesses culturais do lazer como quisesse. No entanto, a realidade é que as pessoas acabam por reduzir suas práticas de 
lazer às mesmas atividades de sempre e, na maioria das vezes, não por desejo, mas por falta de opção (MARCELLINO, 1996).

\section{Lazer e Educação}

Essa falta de opção introduz uma reflexão sobre a necessidade de inserção do lazer no campo da educação. Assim, quando pensamos nesses dois campos, a primeira constatação a ser feita é a de que é preciso práticas pedagógicas que façam com que as pessoas sejam preparadas para exercer um lazer de qualidade. É o que chamamos de educação para o lazer. Há, portanto, um conteúdo a ser trabalhado com os educandos que é fundamental para que eles sejam capazes de exercer sua cidadania e sua característica de ser humano integral de forma plena, que é o lazer. Segundo Camargo (2002), estamos distantes de atingir a civilização do lazer, em que haja a ocupação do tempo livre com ações de diversão e desenvolvimento pessoal efetivos.

A Carta Internacional de Educação para o Lazer (1993), ao tratar desse tema dentro do ambiente escolar estabelece que "a meta geral da educação para o lazer é ajudar estudantes em seus diversos níveis a alcançarem uma qualidade de vida desejável através do lazer". De acordo com esse documento, isso gera impactos em toda a sociedade, ao se estimular valores, atitudes, conhecimento e aptidões do lazer por meio do desenvolvimento pessoal, social, físico, emocional e intelectual. Sugere, ainda, a fim de atingir essa meta, que a educação para o lazer seja parte integrante de ampla variedade de estudos, atividades e experiências em cada estágio do ensino formal e informal e propõe, dentro das estruturas formais de educação, incorporar o lazer em todas as atividades educacionais e culturais, dentro e fora da escola. 
Assim, a questão da educação para o lazer é uma necessidade reconhecida mundialmente na preparação desempenhada nos três níveis de ensino, a ser executada não só pela escola, mas por toda a sociedade, como é tratada a educação brasileira constitucionalmente, em seu art. 205, o qual afirma que a promoção e o incentivo da educação deve ser feita "com a colaboração da sociedade, visando ao pleno desenvolvimento da pessoa, seu preparo para o exercício da cidadania e sua qualificação para o trabalho (BRASIL, 1988).

Uma segunda reflexão é que o lazer é também instrumento de educação. Suas atividades, que alguns podem enxergar apenas como passatempos, têm em sua razão de ser a missão de trabalhar conhecimentos, valores, condutas e comportamentos (PIMENTEL; SANTOS; BOARETTO, 2014; MELO; ALVES JUNIOR, 2003). É o que se denomina educação pelo lazer, que não é das tarefas mais simples, embora aparentemente o seja.

O ambiente escolar não possui em seu currículo formal a inclusão da educação para o lazer, e também pouco reconhece o lazer como instrumento pedagógico. Ao contrário, se apega cada vez mais aos formalismos e seriedades que em nada se assemelham ao universo infantil, na tentativa de criar adultos mirins, vetando as suas possibilidades criativas e questionadoras. Nesse aspecto, de acordo com Rolim (1989, p. 30), o indivíduo tem três opções de interação com o meio: resistir a ele, reagindo ou fugindo das pressões do mundo; utilizá-lo para desenvolver suas potencialidades; ou ainda participar da sua existência, ao adaptar-se ao mundo e adaptá-lo a si, em um movimento de transformação. Dessa forma, cabe à escola aproveitar os recursos do lazer e suas potencialidades pedagógicas e propiciar meios para criar indivíduos que utilizam e participam de seu meio, sem resistir. Isso é possível por meio de atividades 
lúdicas dirigidas que os induzam à reflexão sobre o mundo em que vivem e sobre as suas possibilidades, sem estarem presos a regras e moldes pré-estabelecidos. É pela experimentação do ser que a pessoa é capaz de ampliar sua visão e optar por ser quem é.

\section{O Profissional de Lazer na Educação}

Diferentemente do que acontece dentro da escola, esses recursos pedagógicos de aprendizados de conteúdos e de desenvolvimento humano proporcionados pela educação para e pelo lazer são utilizados indiscriminadamente em atividades extracurriculares desenvolvidas fora do ambiente escolar. Para tanto, é preciso inserir o profissional do lazer nesse contexto, tal como está inserido em ações de planejamento e execução de vivências, coordenação de ações, assessoria na implementação de políticas públicas, dentre outras (ISAYAMA, 2003, p. 63).

O senso comum, sem conhecimento de causa, acredita que a única profissão existente no lazer é a do recreador, caracterizado muitas vezes como o "palhaço" que executa atividades soltas, com o objetivo de esvaziar a mente das pessoas. No entanto, esse profissional administra equipamentos e serviços administrativos diversos, planeja e realiza animação e, principalmente, trabalha pela manutenção dos espaços e das ações (PINA, 1995). Portanto, a formação e a experiência desse profissional devem ser as mais diversificadas possíveis, a fim de evitar a especialização do conhecimento. Segundo Marcellino (2003, p. 15), “o animador sociocultural tem diferentes formações, e isso é extremamente necessário, pela própria abrangência da área cultural”. Assim, o lazer é multiprofissional e interdisciplinar (PEREIRA et al., 2015). No entanto, a literatura nos indica que esse ideal ainda não faz parte da realidade, pois ainda 
predomina a ilusão de que esses profissionais são natos e que não necessitam de formação constante (ISAYAMA, 2003).

Quando nos referimos a um profissional do lazer, algumas características quanto à sua postura profissional devem ser buscadas, dentre elas: formação, liderança, comunicação, criatividade, organização, atualização e senso crítico (MELO; ALVES JÚNIOR, 2003). Tão importante quanto esses aspectos, ainda de acordo com esses autores, é o investimento do profissional que pretenda trabalhar no âmbito da cultura no seu próprio lazer e na expansão da sua percepção das mais diversas formas de manifestações. Nem sempre isso corresponde à realidade, visto que a formação cultural dos estudantes que serão futuros educadores de sensibilidades é restrita. É preciso que o indivíduo que pretenda trabalhar com lazer conviva o máximo possível com o tema, pois isso contribuirá para que sua atuação profissional saia de uma simples brincadeira vazia para propostas de reflexões e intervenções no meio.

Por fim, esclarecemos que a utilização do termo animador sociocultural deve-se à maior precisão quanto ao que esperamos ser seu maior compromisso políticopedagógico: educação para e pelo lazer. Sua vantagem em relação a outros tipos de educadores é a de poder se utilizar, para o processo educativo, dos diversos interesses culturais do lazer, o que lhe promove maior flexibilidade nas suas intervenções pedagógicas (MELO; ALVES JÚNIOR, 2003).

Portanto, os objetivos deste trabalho foram verificar como o lazer, vivenciado por meio de um programa de atividades fora da escola, pode promover um processo de educação, e qual a percepção de futuros animadores socioculturais sobre lazer, educação e a relação entre ambos. 


\section{Sobre o Projeto Escola no Campo}

O Projeto Escola no Campo foi desenvolvido em 2003 por uma psicóloga, pósgraduada em andragogia empresarial com ênfase em recursos humanos e em gestão de projetos, pesquisadora na área de aprendizagem organizacional e diretora de relacionamentos de uma empresa de turismo. À época, o proprietário de uma fazenda hotel localizada em Padre Bernardo, no Estado de Goiás, solicitou a ela que escrevesse um projeto que aumentasse a sua taxa de ocupação nos dias de semana, e que essa ação fosse voltada para a educação. Esse pensamento condiz com a concepção de Stigger (2003, p. 117), que propõe "identificar o espaço do lazer como um espaço pedagógico e o profissional como um educador."

Ela então, por meio de estudos dos Parâmetros Curriculares Nacionais, os PCNs, verificou que era necessário que as escolas trabalhassem com os alunos temas transversais, assuntos esses que não correspondem às disciplinas tradicionais trabalhadas dentro de sala de aula. Dentre esses temas, estão incluídos "ética, pluralidade cultural, meio ambiente, saúde e orientação sexual” (MACEDO, 1998, p. 23). Nasceu então o Projeto Escola no Campo, cujo objetivo é o de promover atividades educativas práticas nas mais diversas áreas do conhecimento e vivenciar dias de pesquisa de campo, unindo ecologia, cultura e lazer. Para tanto, as escolas contratam os serviços da empresa. Segundo a mentora do projeto, "não é negócio da escola fazer viagem, não é o negócio da escola fazer somente recreação, e a gente compõe esse quadro com a escola". Ainda segundo ela, o projeto funciona em parceria com a escola e com o local turístico, a fim de viabilizar "a imersão do aprendizado interdisciplinar".

$\mathrm{Na}$ fazenda, alunos do $5^{\circ}$ ao $9^{\circ}$ ano do ensino fundamental das escolas particulares do Distrito Federal participam de uma série de atividades. Algumas delas 
são fixas dentro do cronograma da saída, como as refeições; outras são determinadas pelas escolas, que as escolhem dentre uma série de opções, conforme "cardápio" da empresa. A permanência dos alunos no estabelecimento pode durar de dois a três dias. Antes de a saída acontecer, a escola determina à empresa qual o seu grande foco: às vezes, ela quer enfatizar a questão do relacionamento entre os alunos, do respeito aos colegas; outras vezes, ela quer aproveitar o momento para vivenciar a vida rural, ter contato com aspectos da ecologia. Colhida essa informação, a empresa se adapta à demanda da escola, por meio do trabalho dos seus guias.

Os guias são estudantes universitários selecionados pela empresa de turismo que, junto com os professores e com o pessoal de apoio da fazenda, conduz o trabalho de educação no local. Para tanto, eles precisam estar aptos a educar. "A natureza do projeto é preparada para ter os guias com uma responsabilidade social sobre a educação infantil. É o que move o projeto", afirma a mentora do projeto. Portanto, a metodologia do processo seletivo desses guias desenvolvida por ela segue o seguinte raciocínio: é preciso que as escolas ampliem a visão de mundo dos alunos, fora da sala de aula, de forma não tradicional, de acordo com o PCN, então faz-se necessária uma equipe multidisciplinar que tenha uma visão de mundo e uma percepção ampliada. Assim, ela declarou: “eu não posso pegar a visão de um profissional, de um perfil. Eu preciso de vários perfis. É isso que eu pensei”. Dessa maneira, o critério de seleção dos guias segue a linha de que é preciso uma equipe multidisciplinar, tal qual deve ser uma equipe de lazer, como nos coloca a literatura pesquisada.

As competências básicas buscadas na seleção dos candidatos seguem rigorosamente os seguintes critérios: deve estar cursando uma faculdade, sem restrição de curso, visto que o projeto é multidisciplinar; deve necessariamente gostar de 
crianças, e comprovar com exemplos da sua vida cotidiana esse contato próximo; deve amar a natureza e realizar atividades de ecoturismo; e, por fim, uma competência não obrigatória, mas desejável, é possuir alguma habilidade artística, esportiva, cultural, ou que realize algum tipo de trabalho social. A partir de então, selecionada a equipe, é feita uma capacitação, executada da seguinte forma: um momento comportamental e outro momento prático-teórico.

Dentre as dificuldades encontradas, o projeto, que é de caráter educacional, com vistas ao aprendizado de forma lúdica de diversos conteúdos e valores, esbarra nas demandas das escolas de lazer por si só. A gestora do projeto explica que isso se deve à quantidade de atividades educacionais que hoje estão presentes dentro da escola, como feiras, comemorações e torneios, o que antigamente, segundo ela, era muito mais restrito. No entanto, o que acontece na prática é que, ao chegar à fazenda, as educadoras das escolas acabam, sim, aproveitando a situação para dar aulas leves e fazer a ligação entre os ensinamentos dados em sala de aula e a realidade, sempre com o auxílio dos guias. Portanto, o projeto mantém o seu perfil educacional.

Interessante analisarmos que os objetivos da animação cultural são, sempre buscando reflexões sobre o papel do sujeito: maior compreensão das pessoas em relação a si próprias e ao mundo que as cerca; maior participação de todos nas questões sociais; preparação para empreender mudanças na sociedade (ISAYAMA, 2003, p. 73). São exatamente dessas premissas que o projeto se utiliza. Como exemplo podemos citar depoimentos de pais e professores que relatam que os alunos, após participarem do projeto, voltaram para casa com uma nova consciência sobre o desperdício da água e das consequências disso para o planeta, mudando seus hábitos e, principalmente, disseminando esses conhecimentos para a família e para os amigos. É a esse tipo de 
contribuição que o projeto se propõe, sendo uma das possibilidades de se trabalhar os quatro pilares da educação da UNESCO, quais sejam "aprender a conhecer, aprender a fazer, aprender a viver juntos e aprender a ser" (CANDURO, 2003, p. 36).

Faz-se necessário esclarecer que, quando utilizamos os termos guia, monitor e animador neste trabalho, estamos nos referindo especificamente ao animador sociocultural. A utilização desses termos se deve à forma como a própria empresa de turismo denomina os componentes da sua equipe de trabalho para o Projeto Escola no Campo.

\section{Materiais e Métodos}

A pesquisa realizada foi de caráter exploratório e descritivo, cujos objetivos, segundo Gil (2002, p. 41-42) são respectivamente o de "proporcionar maior familiaridade com o problema, com vistas a torná-lo mais explícito ou construir hipóteses" e o do "estabelecimento de relações entre variáveis".

Para tanto, foram utilizados como procedimentos técnicos pesquisa bibliográfica, embasada em livros e artigos científicos, e estudo de campo, desenvolvido por meio de observação do processo de formação dos animadores, de aplicação de questionários com os envolvidos e de entrevista como a organizadora de um curso de formação. A utilização desses procedimentos é fundamental para maior fidedignidade dos dados. A pesquisa bibliográfica permite "ao investigador a cobertura de uma gama de fenômenos mais ampla do que aquela que poderia pesquisar diretamente" (GIL, 2002, p. 45). Com esse arcabouço teórico, a pesquisa de campo buscou o aprofundamento das questões propostas em uma população específica, com a utilização de recursos de natureza quantitativa e qualitativa. 
Assim, a amostra analisada consistiu na turma de cinco estudantes universitários de diversas áreas, selecionados a exercer o papel de monitores no Projeto Escola no Campo, realizado na Fazenda Hotel Mestre D’Armas, em Padre Bernardo - GO.

A fim de manter a ética na pesquisa, os voluntários assinaram um Termo de Consentimento Livre e Esclarecido antes de iniciar sua participação. Além disso, este trabalho foi aprovado pelo Comitê de Ética em Pesquisa - CEP da Universidade Católica de Brasília - UCB, sob parecer consubstanciado UCB 051/2010, estando de acordo com as normas estabelecidas pela Resolução Nº CNS 196/96, à época vigente.

Para coletar os dados, foram aplicados questionários com perguntas abertas e fechadas com os estudantes, antes do início do treinamento realizado para a execução de suas atividades. Esses dados foram analisados por meio de dados descritivos (frequência). Também foi feita uma entrevista com a Diretora de Relacionamentos de uma empresa de turismo e mentora do projeto.

Em seguida iniciou-se o processo de formação, realizado no dia 10 de setembro de 2013, na sede da empresa de turismo localizada no Guará II - DF, às 14h, e conduzido pela diretora de relacionamentos da empresa e mentora do Projeto Escola no Campo. Primeiramente foi feita uma apresentação da empresa, do projeto e de suas características, seguida de uma exposição de aspectos sobre o perfil e postura dos guias. Segundo a mentora do projeto, "a gente faz eles enxergarem que eles têm esse perfil, e o que a gente espera disso. Eles podem. Eles podem fazer algo". Por fim, houve uma conversa sobre as formações e perspectivas de contribuição com o trabalho de cada um. Essa postura vai ao encontro da ideia de Isayama (2003, p. 59), ao discorrer sobre a necessidade, dentro do aspecto profissional, de "compreensão sobre uma série de questões gerais acerca da temática, bem como um mapeamento sobre como cada uma 
das áreas poderá contribuir com os seus saberes específicos e intervir nesse campo". Os guias foram convidados em todos os momentos a participar do processo de construção do projeto, que possui uma estrutura flexível, sendo construído conjuntamente por empresa, monitores e escolas.

Após essa primeira etapa, o treinamento continuou no dia 14 de setembro de 2013 na Fazenda Hotel Mestre D’Armas - GO, local em que sempre acontecem as atividades do projeto. Nesse momento, os guias fizeram o reconhecimento do local, foram instruídos sobre o cronograma das saídas pedagógicas e fizeram algumas das possíveis trilhas a serem realizadas durante o projeto.

\section{Resultados e Discussão}

Participaram do questionário preliminar por livre consentimento 2 mulheres e 3 homens, com média de idade igual 26,6 anos (19 e 37). Desses participantes, 80\% possui experiência profissional de mais de 2 anos e $20 \%$ não possui nenhuma experiência profissional. Esses profissionais são todos estudantes universitários dos cursos de Pedagogia, Biologia e Educação Física. Essa característica de multidisciplinaridade encontrada na equipe constituída faz parte da filosofia do projeto estudado. Essa formação é essencial para o sucesso do objetivo do trabalho. De acordo com Melo e Alves Júnior (2003, p. 77), “o ideal seria montar uma equipe multidisciplinar, que, atuando em conjunto, dialogaria com diferentes visões e comporia o projeto com base em diversas experiências". Esse fato mostrou-se importante, tanto para o bom desenvolvimento do trabalho em campo, que necessita de diversos conhecimentos, como para a contribuição na formação dos guias que, em contato com 
pessoas de outras áreas, podem aprender mais. E é exatamente assim que a literatura nos diz que deve ser uma equipe de lazer: multidisciplinar.

Quando questionados sobre o motivo de buscarem aquela seleção, 62,5\% das respostas afirmaram ser por motivo profissional, $25 \%$ por motivo pessoal e $12,5 \%$ financeiro. Nenhum participante afirmou ter um motivo social para procurar aquele processo seletivo.

Em relação à sua percepção quanto à importância da reflexão sobre o lazer para os alunos que estão se formando, $80 \%$ dos participantes respondeu ser alta e $20 \%$ muito alta. Isso nos leva a crer que, para essa amostra, a educação para o lazer é de suma importância. Já em relação à importância do lazer para a educação/processo educativo, $60 \%$ respondeu que acredita ser alta e $40 \%$, muito alta. Ou seja, os sujeitos amostrais acreditam que a educação pelo lazer é ainda mais importante.

Essas respostas condizem com o resultado de $100 \%$ que afirma já ter ouvido falar em educação pelo lazer e de $80 \%$ que já ouviu falar em educação para o lazer. Uma das probabilidades dessa pequena diferença ter acontecido é que a educação para o lazer acaba sendo segmentada aos profissionais da área da Educação Física, não sendo abraçada como uma causa pela Biologia, por exemplo.

Sobre o questionamento a respeito do que motiva as crianças a executarem uma atividade, quatro participantes afirmaram saber a resposta e, dentre essas, a diversão foi a mais citada. Segundo Camargo (2002, p. 34), existem quatro grandes motivações para toda e qualquer diversão: a aventura, a competição, a vertigem e a fantasia. Dentre outros aspectos, essas motivações "permitem, no caso da criança, a maturação do homo faber, do homem que um dia precisará associar o reino da expressão ao reino da necessidade, a diversão ao trabalho". E por que é importante saber dessas motivações? 
Motivar as crianças acarreta maior probabilidade de elas efetivamente absorverem as habilidades e conhecimentos fundamentais para que estejam realmente preparadas para atuar na vida real. E essas motivações estão embutidas nas atividades lúdicas. "O lúdico, o prazeroso, o inovador, o dinâmico são elementos indissociáveis da aprendizagem e a ela inerentes em todos os tempos e espaços da escola cidadão" (SILVA, 2003, p. 53).

Todos os guias afirmaram acreditar que a experiência dos alunos no Projeto Escola no Campo contribuirá para a formação pessoal, social e acadêmica dos mesmos. Para discutir essa questão, iniciamos com a declaração de Cauduro (2003, p. 32): "Somos simultaneamente seres cósmicos, físicos, biológicos, culturais, cerebrais, espirituais etc." O processo educacional deve ser focado no desenvolvimento integral do ser humano, e não apenas no aspecto cognitivo. É preciso preparar os alunos para serem seres completos e capazes de interagir e intervir na sua própria realidade. Um processo de educação pelo lazer pode contribuir para isso, conforme explicita Silva (2003, p. 51), ao aumentar a autoestima e ampliar a possibilidade de produtividade escolar e de aprendizado efetivo, estimulando o desenvolvimento do aluno de forma integral. Como, de acordo com Melo e Alves Júnior (2003, p. 32), “as atividades de lazer são atividades culturais, em seu sentido mais amplo, englobando os diversos interesses humanos, suas diversas linguagens e manifestações", as atividades de lazer também podem contribuir com esse crescimento do aluno de forma integral.

Ao serem questionados sobre os aprendizados que acreditam que as crianças obtenham após participar do Projeto Escola no Campo, foram diversas as respostas, as quais transitaram entre aprendizados acadêmicos, individuais e sociais. Os aprendizados acadêmicos elencados foram: melhor compreensão de conceitos ecológicos e 
preservação/manutenção do ambiente natural; delimitação do tema "meio ambiente"; pensar no futuro acadêmico; sociedade; cultura; história. Em termos individuais e sociais, a lista de aprendizados foi a seguinte: ser mais atencioso; desenvolver a interação social; ficar mais disposto a estudar; vivência de contato com a natureza; vida em grupo; responsabilidade por si (autonomia); melhor diferenciação de ambiente urbano/ rural; consciência ecológica; trabalho em grupo; respeito aos colegas; paciência; obediência; dar valor a pequenas coisas, mesmo simples que seja. É possível verificar que para esses guias, os possíveis aprendizados dos alunos vão além de complementação das disciplinas escolares. A vivência com a natureza e com os colegas poderá ensinar-lhes questões de cunho individual, como autonomia, respeito, paciência, além de passar a dar valor às pequenas coisas, e de cunho social, como conviver em grupo e em sociedade. Mas, segundo a gestora do projeto, um dos maiores aprendizados dos alunos ao vivenciarem o Projeto Escola no Campo é o que ela chama de "autonomia restritiva”. Ela explica que, na maioria das vezes, é a primeira vez que essas crianças estão dormindo fora do contexto familiar. Lá elas aprendem que não podem fazer tudo o que querem, que devem seguir horários, que devem colaborar na arrumação do quarto, que devem respeitar o colega, os professores e a natureza. Elas deixam de ser soberanas e passam a reconstruir a sua realidade. " $E$ fora do quarto, fora da sala, fora do ambiente familiar, o aprendizado é muito diferente, ele está livre, ele está no mato", explicita. Realmente, o contato com a natureza permite um salto de aprendizado ao aluno. Para Oliveira (1995, p. 109), diferentemente do ensino formal, realizado entre quatro paredes, "esses espaços, que permitem o contato próximo à natureza, estimulam os sentidos, aguçam a curiosidade e o interesse e inspiram sentimentos de liberdade e prazer". Esclarecemos aqui que, por mais que façamos uma classificação para fins 
didáticos desses aprendizados, sabemos que é difícil dissociar uma coisa da outra, isso porque o ser humano é um ser completo e a "natureza, conhecimento e prazer estão indissoluvelmente ligados, a despeito da intenção do próprio homem de fragmentá-los" (p.110).

Entre os monitores, $60 \%$ deles afirmaram que o lazer possui uma importância muito alta em sua vida e $40 \%$ uma importância alta. Essa é uma reflexão importante: é preciso que os profissionais do lazer se dediquem à sua própria prática de maneira cuidadosa. Segundo Melo e Alves Júnior (2003, p. 83), “os alunos frequentam pouco cinemas, teatros, centros culturais, museus etc.", geralmente por falta de recursos financeiros e pelas distâncias dos espaços de lazer. O que se percebe é que profissionais de lazer possuem os mesmos problemas da população em geral no que diz respeito ao usufruto do seu tempo. No entanto, esses devem se esforçar para vivenciar outras formas de interesses culturais, a fim de ampliar seu campo de visão e de atuação profissional. É o que afirma Pina (1995, p. 127), ao declarar que o animador sociocultural, "deve acompanhar as diferentes programações culturais que acontecem em sua comunidade e em sua cidade e obter informações sobre aquelas que não pode acompanhar diretamente".

Ao se pronunciarem sobre encarar ou não o trabalho a ser desempenhado como lazer, quatro dos cinco participantes responderam que sim. Como vimos, lazer é aquela atividade realizada no tempo livre de obrigações. Portanto, período de trabalho não é considerado lazer. No entanto, essa questão é determinante na questão da atuação do profissional de lazer. Segundo Isayama (2003, p. 65),

Muitas vezes, profissionais de educação física buscam atuar no âmbito do lazer por pensar que estão conseguindo um trabalho fácil, no qual se tenha uma "boa vida", acreditando na ideia de que o que se faz não é trabalhar, e sim brincar o dia todo - e o que é melhor, contando com uma remuneração para isso. Essa visão traz à tona a falta de 
Paula leite A. de Macedo, Gislane Ferreira de Melo e Tânia Mara V. Sampaio

componentes lúdicos no trabalho das pessoas em geral, fazendo com que o trabalho no campo do lazer seja confundido com o próprio lazer desses profissionais. De acordo com Stoppa e Isayama (1999), não é clara a distinção entre lazer e trabalho na ação do profissional que atua nessa esfera. Em geral, há uma tendência a confundir as experiências criativas, lúdicas e expressivas com o seu próprio trabalho. Por esse motivo, muitas pessoas tendem a restringir o entendimento sobre a intervenção profissional no lazer, muitas vezes, considerando o trabalho "fácil" e "gostoso" de ser realizado, em comparação com aqueles que não apresentam nenhuma possibilidade lúdica. Nesse caso, ignoram que esse trabalho requer fundamentos técnicos, pedagógicos, político-culturais e sociais, além de contar com os componentes de obrigação que permeiam os acordos de trabalho"(grifo nosso).

Entre os participantes, $60 \%$ afirmaram se espelhar em alguém para realizar esse trabalho, dentre professores, treinadores e chefes. Dentre as qualidades pessoais dessas pessoas apontadas como referência, foram citadas: extrovertido, dinâmico, engraçado, proativo, comunicativo, animado, não deixa ninguém parado, guerreiro, educador, pessoa sem igual, pessoa de coração puro. É interessante notar que características como “extrovertido", “engraçado", animado", "não deixa ninguém parado" corroboram com a visão generalizada que esses profissionais devem ser, acima de tudo, showmans. Essa ideia é um equívoco. A extroversão, segundo Isayama (2003, p. 64) é um aspecto que causa, muitas vezes, "uma grande confusão, pois o bom profissional é associado à pessoa mais engraçada, capaz de fazer todos caírem na gargalhada."

A característica de ser um educador foi pouco comentada, fazendo-nos crer que entre os guias impera a noção de que o que vale mesmo é ser engraçado. Não que essa marca não seja desejável, mas não é crucial. No entanto, todos eles afirmam se sentirem preparados para educar. Isso nos leva a induzir que, por mais que não pensem ser essa a sua função principal nesse projeto, eles também devem exercer esse papel.

A expectativa dos participantes, antes de começarem efetivamente o seu trabalho, é a de que trabalhar no Projeto Escola no Campo seja aprendizado, 
crescimento profissional, lazer e descanso, desafiador, oportunidade de disseminar conhecimentos e educar. Assim, é possível inferir que há uma vontade desses profissionais de crescerem com esse trabalho, bem como que essa experiência de educação para o pelo lazer poderá ser incorporada por eles como possibilidade de intervenção nos seus campos de atuação.

\section{Conclusão}

Após a análise destes resultados podemos responder aos nossos objetivos de forma pontual, ou seja, de acordo com a pesquisa realizada, o lazer, vivenciado por meio de um programa de atividades fora da escola, promove um processo de educação por meio da educação para e pelo lazer. Foi possível verificar-se a vontade e a percepção positiva que os futuros animadores socioculturais possuem em relação à utilização da educação para e pelo lazer e de seus benefícios. Para eles, esse projeto contribuirá na formação pessoal, social e curricular dos alunos, e os aprendizados adquiridos são não apenas acadêmicos, mas principalmente individuais e sociais.

\section{REFERÊNCIAS}

BRASIL. Constituição. Constituição da República Federativa do Brasil, 1988. Brasília: Senado Federal, Centro Gráfico, 1988. 292p.

CAMARGO, L. O. L. Educação para o lazer. São Paulo: Moderna, 2002.

CARTA INTERNACIONAL DE EDUCAÇÃO PARA O LAZER. World Leisure and Recreation Association. Jerusalém - Israel, 2 a 4 de agosto de 1993 e ratificada pelo Conselho da WLRA Jaipur - Índia 3 de dezembro de 1993. Disponível em: https://cev.org.br/biblioteca/carta-internacional-educacao-para-o-lazer/. Acesso em: 27 mai. 2013.

CAUDURO, M. T. O profissional de educação física e suas competências específicas. In: MARCELLINO, N.C. (Org.). Formação e desenvolvimento de pessoal em lazer e esporte. Campinas, SP: Papirus, 2003. p. 31-45. 
DUMAZEDIER, J. Lazer e cultura popular. São Paulo: Perspectiva; 1973.

GIL, A. C. Como elaborar projetos de pesquisa. 4. ed. São Paulo: Atlas, 2002.

GOMES, C. Lazer: necessidade humana e dimensão da cultura. Revista Brasileira de Estudos do Lazer, v. 1, n. 1, p. 3-20, 2014.

ISAYAMA, H. F. O profissional da educação física como intelectual: atuação no âmbito do lazer. In: MARCELLINO, N.C. (Org.). Formação e desenvolvimento de pessoal em lazer e esporte. Campinas, SP: Papirus, 2003. p. 59-79.

MACEDO, E. F. Os temas transversais nos Parâmetros Curriculares Nacionais. Química Nova na Escola, n. 8, p. 23-27, 1998.

MARCELlinO, N. C. Estudos do lazer: uma introdução. Campinas: Autores Associados, 1996.

. A formação e o desenvolvimento de pessoal em políticas públicas de lazer e esporte. In: MARCELLINO, N.C. (Org.). Formação e desenvolvimento de pessoal em lazer e esporte. Campinas: Papirus, 2003. p. 9-17

MELO, V. A.; ALVES JUNIOR, E. D. Introdução ao lazer. Barueri: Manole, 2003.

OLIVEIRA, C. Lazer, educação e meio ambiente: a experiência do CIPAM. In: MARCELLINO, N.C. (Org.). Formação e atuação profissional. Campinas: Papirus, 1995. p. 103-110.

PEREIRA, A. et al. A atuação profissional no campo do lazer: reflexões sobre aspectos éticos. LICERE-Revista do Programa de Pós-graduação Interdisciplinar em Estudos do Lazer, v. 18, n. 2, p. 243-261, 2015.

PIMENTEL, G.; SANTOS, S.; BOARETTO, J. Educação para e pelo lazer: um diálogo étnico e cultural. In: SAMPAIO, T. M. V. (org.). Lazer e cidadania: partilha de tempo e espaços de afirmação da vida. Brasília: Universa, 2014, p. 105 -128.

PINA, L. W. Multiplicidade de profissionais e de funções. In: MARCELLINO, N.C. (Org.). Formação e atuação profissional. Campinas: Papirus, 1995. p. 117-130.

ROLIM, L. C. Educação e lazer - a aprendizagem permanente. São Paulo: Ática, 1989.

SCHWARTZ, G. M. O conteúdo virtual do lazer - contemporizando Dumazedier. LICERE-Revista do Programa de Pós-graduação Interdisciplinar em Estudos do Lazer, v. 6, n. 2, 2003.

SILVA, J. V. P.; SAMPAIO, T. M. V. O lazer e suas diversas faces. In: SAMPAIO, T. M. V.; SILVA, J. V. P. (Org.). Lazer e cidadania: horizontes de uma construção coletiva. Brasília: Universa, 2011.p. 45 -61. 
SILVA, P. M. Formação e atuação dos coordenadores culturais nas escolas da Rede Municipal de Ensino de Porto Alegre. In: MARCELLINO, N. C. (Org.). Formação e desenvolvimento de pessoal em lazer e esporte. Campinas: Papirus, 2003. p. 47-57.

STIGGER, M. P. Políticas públicas em esportes e lazer: considerações sobre o papel do profissional educador. In: MARCELLINO, N.C. (Org.). Formação e desenvolvimento de pessoal em lazer e esporte. Campinas: Papirus, 2003. p. 101-120.

\section{Endereço das Autoras:}

Paula Leite Antunes de Macedo

Universidade Católica de Brasília

Mestrado e Doutorado em Gerontologia

Quadra QS 7 Areal - Águas Claras

Brasília - DF - 71.966-700

Endereço Eletrônico: paulamilk2002@yahoo.com.br

Gislane Ferreira de Melo

Universidade Católica de Brasília

Mestrado e Doutorado em Gerontologia

Quadra QS 7 Areal - Águas Claras

Brasília - DF - 71.966-700

Endereço Eletrônico: gislane.melo@gmail.com

Tânia Mara Vieira Sampaio

Instituto Federal de Goiás - Campus Luziânia

R. São Bartolomeu, s/n - Vila Esperança,

Luziânia - GO - 72.811-580

Endereço Eletrônico: taniamara_sampaio@hotmail.com 